\title{
Chick Lrrn2, a novel downstream effector of Hoxbl and Shh, functions in the selective targeting of rhombomere 4 motor neurons

\author{
Laura C Andreae ${ }^{1}$, Andrew Lumsden ${ }^{1}$ and Jonathan D Gilthorpe*1,2
}

Address: ${ }^{1}$ MRC Centre for Developmental Neurobiology, King's College London, New Hunt's House, Guy's Campus, London, SE1 1UL, UK and ${ }^{2}$ Umeå Centre for Molecular Medicine, Umeå University, 90187 Umeå, Sweden

Email: Laura C Andreae - laura.andreae@kcl.ac.uk; Andrew Lumsden - andrew.lumsden@kcl.ac.uk; Jonathan D Gilthorpe* - jonathan.gilthorpe@ucmm.umu.se

* Corresponding author

Published: 14 July 2009

Neural Development 2009, 4:27 doi:10.1186/1749-8104-4-27
Received: 3I December 2008

Accepted: 14 July 2009

This article is available from: http://www.neuraldevelopment.com/content/4/I/27

(c) 2009 Andreae et al; licensee BioMed Central Ltd.

This is an Open Access article distributed under the terms of the Creative Commons Attribution License (http://creativecommons.org/licenses/by/2.0), which permits unrestricted use, distribution, and reproduction in any medium, provided the original work is properly cited.

\begin{abstract}
Background: Capricious is a Drosophila adhesion molecule that regulates specific targeting of a subset of motor neurons to their muscle target. We set out to identify whether one of its vertebrate homologues, Lrrn2, might play an analogous role in the chick.

Results: We have shown that Lrrn2 is expressed from early development in the prospective rhombomere $4(\mathrm{r} 4)$ of the chick hindbrain. Subsequently, its expression in the hindbrain becomes restricted to a specific group of motor neurons, the branchiomotor neurons of $r 4$, and their premuscle target, the second branchial arch (BA2), along with other sites outside the hindbrain. Misexpression of the signalling molecule Sonic hedgehog (Shh) via in ovo electroporation results in upregulation of Lrrn2 exclusively in $r 4$, while the combined expression of Hoxbl and Shh is sufficient to induce ectopic $L r r n 2$ in $\mathrm{rl} / 2$. Misexpression of $\mathrm{Lrrn} 2$ in $\mathrm{r} 2 / 3$ results in axonal rerouting from the $r 2$ exit point to the $r 4$ exit point and $B A 2$, suggesting a direct role in motor axon guidance.
\end{abstract}

Conclusion: Lrrn2 acts downstream of Hoxbl and plays a role in the selective targeting of $r 4$ motor neurons to BA2.

\section{Background}

The hindbrain is patterned during development along two major axes, anterior-posterior (AP) and dorsal-ventral (DV). This generates a Cartesian coordinate system in which, theoretically, the fate of an individual cell, or group of cells, can be specified by its position relative to these orthogonal axes of positional information [1]. The key regulators of AP patterning for the posterior central nervous system (CNS) are the Hox genes, which are expressed in a segmental fashion in the hindbrain and have anterior expression boundaries that correspond to specific rhombomere boundaries [1-4]. Much as their Drosophila homologues confer segment-specific identity upon the body segments of the fly embryo, the vertebrate Hox genes confer segment-specific identity upon rhombomeres: gain or loss of function results in homeotic transformations [5-10]. Along the DV axis different cell fates are regulated by secreted signalling molecules. Of these, by far the best-studied system is the patterning of the ventral neural tube by graded concentrations of Sonic hedgehog (Shh) [11-13]. Shh is expressed by the floor plate and notochord, and regulates the expression of a 
series of homeodomain transcription factors, which in turn generate sharp domains of expression by crossrepressive effects $[11,14,15]$. Specific and distinct neuronal cell types are then generated from these domains. For example, in the spinal cord, one class of interneuron $\left(\mathrm{V}_{0}\right)$ develops from the region immediately adjacent to the floor plate, while motor neurons are generated from the next most ventral domain.

While the transcriptional components that respond to early patterning signals are increasingly understood, less is known about the downstream targets that directly regulate cellular behaviour, such as specific axonal projections. For example, Hoxb1 is expressed at early stages throughout rhombomere 4 (r4), and loss-of-function mutations in the mouse lead to marked abnormalities of the r4-derived motor neurons $[7,16]$. Furthermore, misexpression of Hoxb1 in basal $\mathrm{r} 2$ can result in a transformation of the presumptive $\mathrm{r} 2$ motor neurons to an r4-like identity (that is, trigeminal to facial), as assessed by the rerouting of these $\mathrm{r} 2$ motor projections from their usual destination of the first branchial arch (BA1) to the facial motor neuron target, BA2 [6]. The misexpression of Hoxb1 must result in critical changes to the cell surface molecules expressed by these motor neurons, such that their axons follow guidance cues appropriate to those of r4. Hoxb1 has the capacity to regulate its own expression (autoregulation), the expression of other Hox genes (cross-regulation) and a number of other transcriptional control genes, such as GATA2, GATA3 and Phox $2 b[6,17$ 19]. Recently, a microarray screen in zebrafish has identified a number of Hoxb1 downstream targets [20]. However, the identities of downstream effector genes, particularly those encoding cell surface guidance molecules, remain largely unknown.

Several generic guidance cues - that is, those acting on all types of motor neuron - have been identified, including chemoattractant cues from their targets [21-24]. However, the existence also of specific cues is made apparent by phenomena such as the misrouting of Hoxb1+ $\mathrm{r} 2$ motor neurons [6], or the abnormal trajectories taken by $\mathrm{r} 5$ facial branchiomotor axons to reach their original target when grafted ectopically [25]. Many of the ligand-receptor systems involved in axon guidance are evolutionarily conserved between invertebrate and vertebrate species $[26,27]$ and several molecules that regulate specific axon targeting events have been identified in Drosophila. For example, the leucine-rich repeat-containing molecules Connectin and Capricious (Caps) are expressed in specific subsets of motor neurons and their muscle targets and regulate axonal targeting in these contexts [28-31]. The closest vertebrate relatives of Caps are members of the Lrrn (leucinerich repeat neuronal) family [32-35]. In this study, we show that one member of this family, Lrrn2, is expressed in $\mathrm{r} 4$ motor neurons and their target, the mesodermal premuscle plate of BA2 in chick. Furthermore, we demonstrate that Lrrn 2 expression is regulated by both Hoxb1 and Shh, and that misexpression of Lrrn 2 in $\mathrm{r} 2 / 3$ can result in routing abnormalities of motor axons. Thus, Lrrn2 appears to function in $\mathrm{r} 4$ motor neurons downstream of Hoxb1 and Shh to integrate both AP and DV signalling components and to participate in the peripheral targeting of $\mathrm{r} 4$ motor axons.

\section{Results \\ Lrrn 2 is expressed in presumptive $r 4$ territory from early stages}

Lrrn2 is first expressed in chick embryos at Hamburger and Hamilton stage 4 (HH4) in a triangular region around Hensen's node (Figure 1A). Expression is activated in the neural plate at HH5 (Figure 1B), becoming more robust by $\mathrm{HH} 7$, when expression also extends to posterior regions (Figure 1C). A striking feature during these early stages is its asymmetric expression on the right-hand side of the node (Figure 1A-C). By HH8, the expression pattern has become increasingly restricted: strong staining is visible in the prospective forebrain (diencephalon), midbrain and hindbrain, with a posterior domain of stronger expression becoming delineated (Figure 1D). By HH9, this domain has resolved into a stripe that corresponds to prospective $\mathrm{r} 4$ (Figure 1E). By HH11, expression is visible not only in $\mathrm{r} 4$, but also in the adjacent mesoderm (Figure 1F). Midbrain and diencephalic expression of Lrrn 2 persists throughout these stages.

To better define the location of the developing stripe of Lrrn2 expression in the hindbrain, double-labelled in situ hybridisation was performed using a chick Hoxb1 probe (Figure 1G-I). At these early stages, the anterior border of Hoxb1 expression corresponds to the $\mathrm{r} 3 / \mathrm{r} 4$ boundary [36]. At HH6-7, the posterior border of Lrrn2 expression was not distinct but showed a clear overlap with Hoxb1 (Figure $1 \mathrm{G}, \mathrm{H})$. By HH8, Lrrn2 upregulation was evident in a domain coincident with the anterior-most staining of Hoxb1 (Figure 1I-K). Thus, Lrrn2 is expressed in the early neural plate with a posterior border that approximates to future $\mathrm{r} 4$ at early stages and later becomes refined specifically to $\mathrm{r} 4$.

\section{Lrrn2 labels post-mitotic motor neurons in $r 4$ and their corresponding target tissue in the second branchial arch}

R4 is the source of a population of motor neurons that innervate BA2 muscles [37]. Analysis of Lrrn2 expression at HH14 (Figure 2A) shows strong staining in the CNS in a ventral domain within $\mathrm{r} 4$ and in non-neuronal cells in BA2. The latter could represent either r4-derived neural crest cells, which migrate into the arch at this stage, or mesodermal cells that give rise to branchial muscle. Staining is also seen in the ventral midbrain. Flatmounting of 

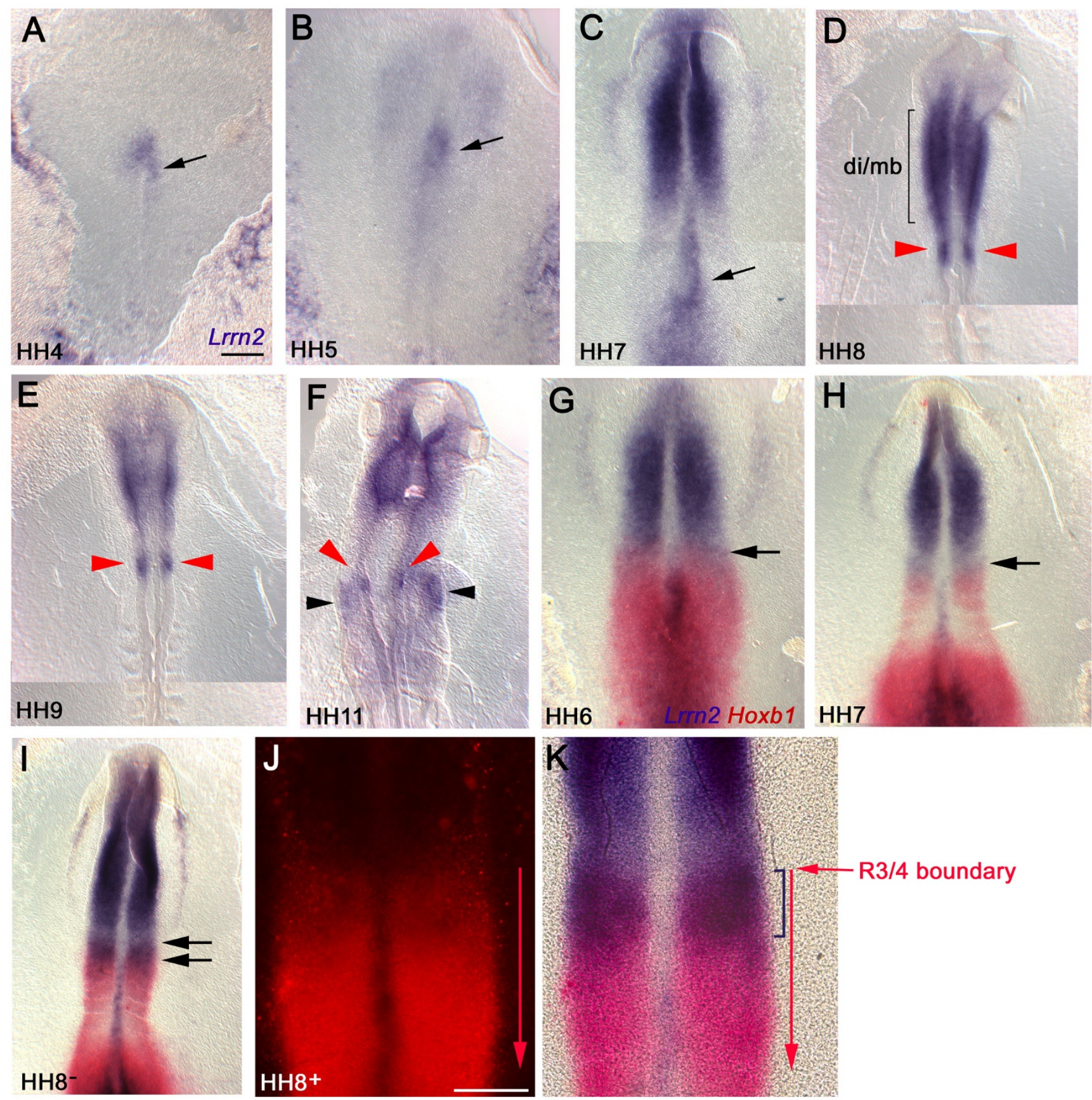

Figure I (see legend on next page) 
Figure I (see previous page)

Time-course of Lrrn2 expression. Chick embryos from HH4-I I following in situ hybridisation for Lrrn2 and Hoxb I. All views are dorsal side up, anterior to the top. (A) $\mathrm{HH}$ 4, (B) $\mathrm{HH}$, (C) $\mathrm{HH}$ 7. Note asymmetric expression of Lrrn2 on the right side of the node (arrows in (A-C)). (D) HH8, (E) HH 9, (F) HHII. Expression of Lrrn2 starts to localise to the $r 4$ region at $\mathrm{HH} 8$ and by $\mathrm{HH} 9$ is clearly distinguishable (red arrowheads in $(D, E)$ ). Strong staining is also seen in the prospective diencephalon-midbrain region (di/mb) (D). At HHII, r4 expression within the neuroepithelium can be seen (red arrowheads), along with expression in the adjacent mesoderm (black arrowheads in (F)). (G-K) Double in situ hybridisation with Lrrn2 (blue) and Hoxbl (red). (G) HH6, (H) HH7; arrows indicate anterior boundary of Hoxbl expression (future r3/4 boundary). (I) HH8: the region between the double, black arrows highlights overlap in expression, corresponding to presumptive $\mathrm{r} 4$. (J) $\mathrm{HH} \mathrm{8}^{+}$: high power view of hindbrain region with fluorescent image of Hoxbl expression where the $\mathrm{r} 3 / 4$ boundary is clear, despite some quenching due to the NBT/BCIP staining of Lrrn2, and (K) brightfield image showing the same. The anterior boundary of the Lrrn2 stripe (bracket) coincides with the anterior boundary of Hoxbl, indicating that Lrrn2 is expressed in early r4. Scale bars: $100 \mu \mathrm{m}$.

the hindbrain shows that Lrrn2 expression is largely restricted to cells immediately adjacent to the floor plate in $\mathrm{r} 4$ corresponding to the progenitor domain for $\mathrm{r} 4$ motor neurons. A few scattered Lrrn2+ cells are also seen more dorsally (Figure 2B).

Motor neurons are generated at $\mathrm{HH} 14$, in response to Shh signalling, from progenitors located adjacent to the floor plate in the CNS ventricular zone. Differentiating, postmitotic motor neurons move radially into the outer, mantle zone and express the transcription factor Islet-1 (Isl1) [38]. To determine whether Lrrn2 expression corresponded to either of these populations, transverse sections at the level of $\mathrm{r} 4$ were examined. Lrrn $2^{+}$cells are located away from the ventricular surface in the mantle zone and, therefore, are likely to be post-mitotic motor neurons (Figure 2C).

Two types of motor neuron are generated in $\mathrm{r} 4$ : the facial branchiomotor (FBM) neurons, which will innervate voluntary muscles of the second branchial arch; and the vestibular-acoustic (VA) efferent neurons, which will innervate hair cells of the inner ear. In the chick, FBM neurons migrate dorsally and extend axons ipsilaterally in a dorsolateral direction to exit the neural tube via the $\mathrm{r} 4$ exit point in the alar plate $[37,39]$. A subpopulation of VA neurons undergoes a characteristic migration in which their cell bodies migrate across the midline after they have already extended axons dorsolaterally to join FBM axons, resulting in a contralateral projection [40]. Lrrn2+ cells seen more dorsally in $\mathrm{r} 4$ were also located in the mantle zone (Figure 2C). Their position is consistent with them being tangentially migrating FBM neurons that have begun their dorsal-ward migration, although this has not been demonstrated. In support of this, no Lrrn2+ cells that could represent a contralateral VA population were seen at the midline.

Lrrn2 expressing cells were also observed in the periphery (Figure 2A, C, D). Cells migrating into the arches from the paraxial mesoderm are known to occupy a ventral territory while neural crest follows a more dorsal route [41]. Lrrn $2^{+}$staining is seen in a more ventral location (Figure 2D), indicating that they are likely to represent migrating mesodermal cells rather than migratory neural crest cells, which normally occupy a dorsal position as shown by the neural crest marker RXR [42] at HH14 (Figure 2E).

At HH18 (Figure 2F), Lrrn2 expression remains intense in ventral $\mathrm{r} 4$ and also in more dorsolateral cells (putative FBM cell bodies). Weaker staining is also seen in r2, including a dorsal population perhaps representing the dorsally migrating trigeminal motor neurons, as well as throughout the ventral motor column in the spinal cord and in the ventral midbrain (Figure $2 \mathrm{~F}$ ). Strong staining is seen in BA2, with little or no staining in BA1 (Figure 2F). Coronal sections through the branchial arches at this stage show Lrrn2 in the core region of BA2 (Figure 2G, H). For comparison, corresponding sections at the same stage of mesodermal marker Tbx1 $[43,44]$ and neural crest markers CRABP1 [45] and Dlx2 [46,47] are also shown (Figure $2 \mathrm{I}-\mathrm{K})$. These demonstrate that mesodermal cells are found in the central core region of BA2 (Figure 2I) while neural crest cells occupy a peripheral territory (Figure 2J, $\mathrm{K})$. This indicates that at HH18 Lrrn2 labels mesodermal cells in BA2.

\section{Lrrn2 expression is responsive to Shh signalling only in r4}

Shh is an important determinant of motor neurons at all AP axial levels of the neural tube and it is well established that artificially increasing the level of Shh signalling results in an increased generation of motor neurons $[12,13]$. To test whether Lrrn2 is induced by Shh in motor neurons, we used in ovo electroporation to misexpress Shh unilaterally in the hindbrain. A plasmid encoding chick Shh (pXeX-Shh) [48] was co-electroporated at HH9-11 with a green fluorescent protein (GFP) expression vector (pCAß-eGFPm5) [49] to mark electroporated cells. Coexpression of the two plasmids was confirmed by in situ hybridisation with a chick Shh probe and antibody stain- 


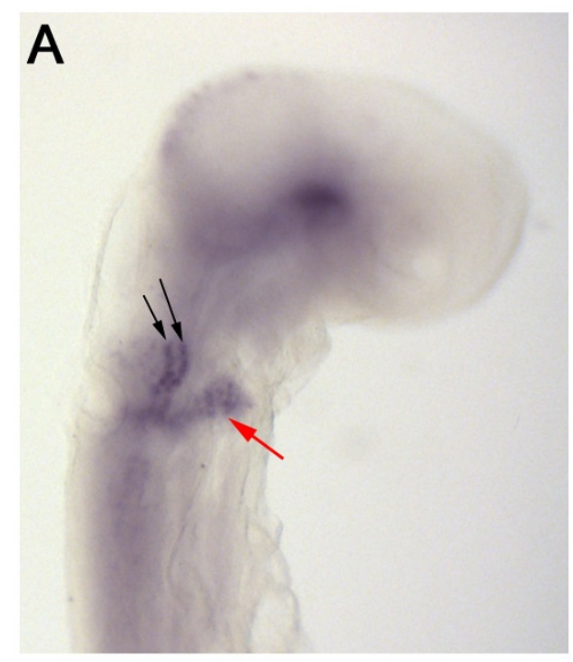

D
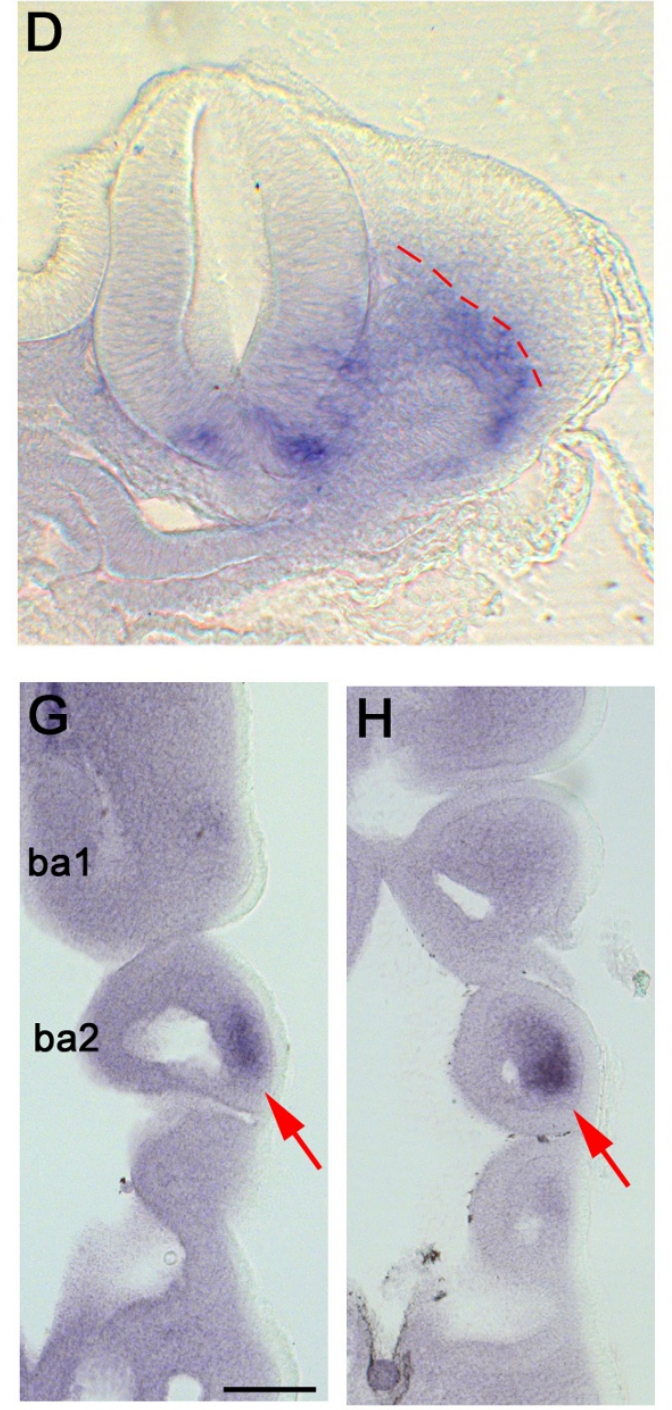
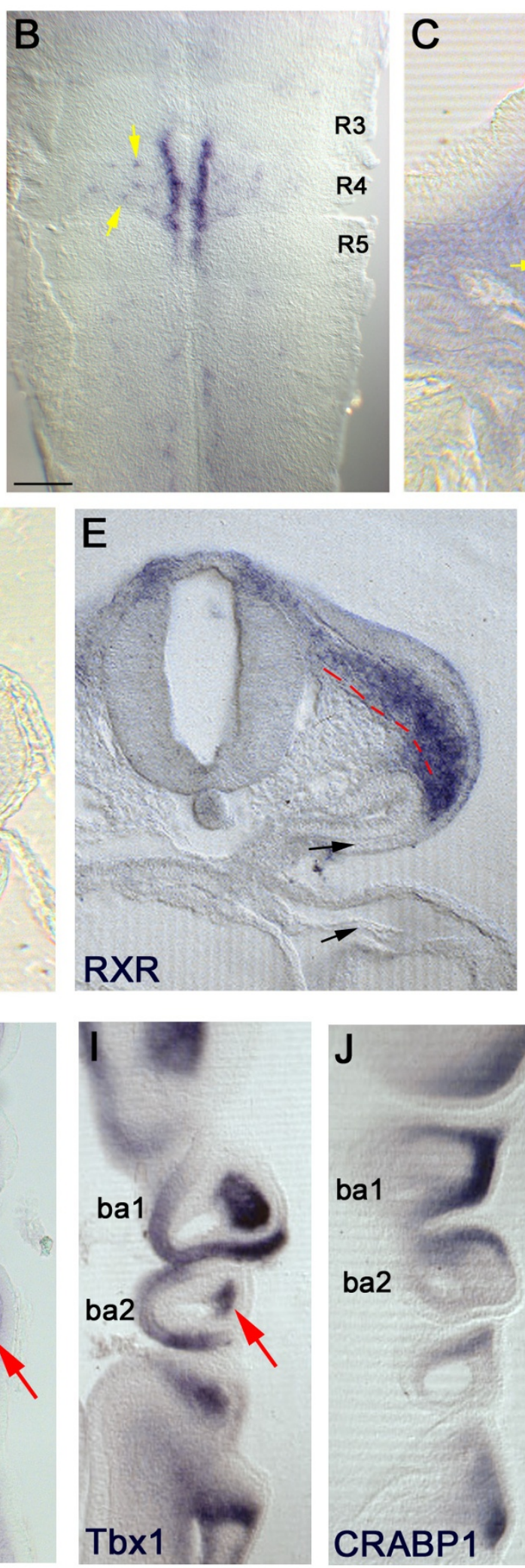

C
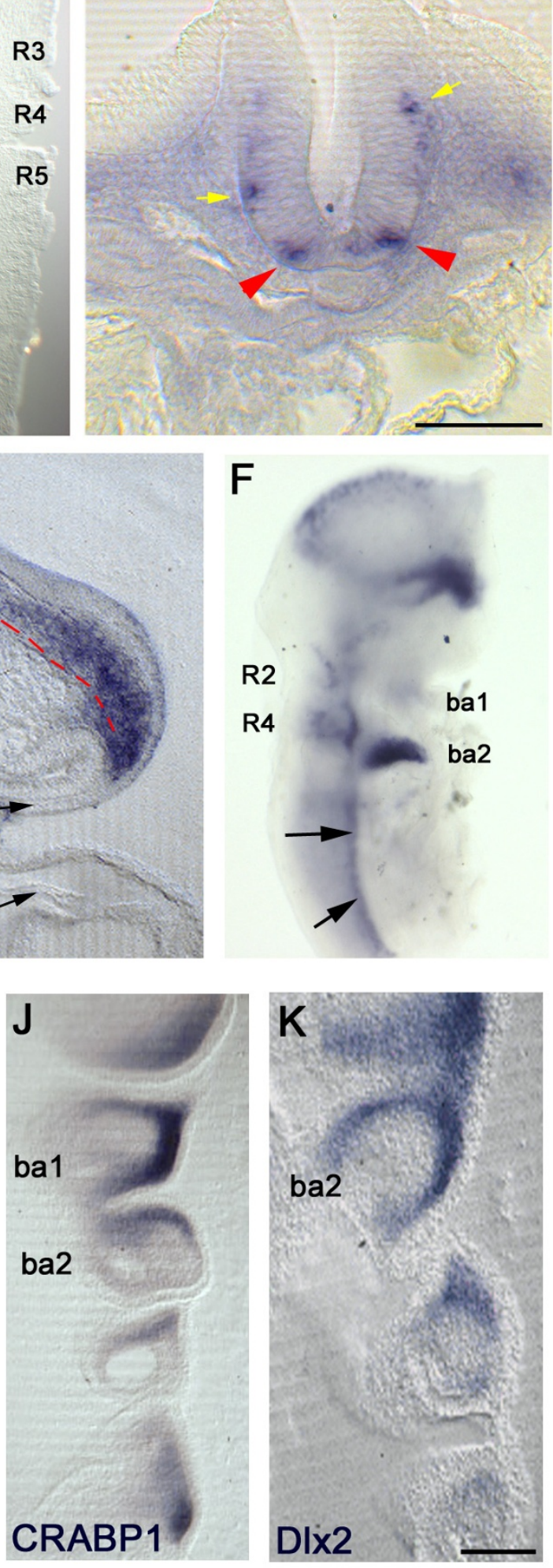

Figure 2 (see legend on next page) 
Figure 2 (see previous page)

Lrrn2 marks rhombomere 4 motor neurons and the second branchial arch. In situ hybridisation with (A-D, F-H) Lrrn2, (E) RXR, (I) TbxI, (J) CRABPI, (K) Dlx2 at HHI4 (A-E) and HHI8 (F-K). (A) Wholemount embryo shows Lrrn2 expression in two stripes in ventral $\mathrm{r} 4$ (black arrows) and in nearby cells within the presumptive BA2 region (red arrow). (B) Flatmounted hindbrain shows Lrrn2 expression restricted to two columns immediately alongside the ventral midline of $r 4$, with a few scattered cells within the body of $r 4$ (yellow arrows). (C) Transverse section through the hindbrain at the level of $r 4$ shows expression in the outer layer (red arrowheads). Yellow arrows indicate more dorsal cells seen also in (B). (D) Next posterior transverse section of the same series as $(C)$ shows staining in the ventrally located mesoderm (below red dashed line). (E) Neural crest marker $R X R$ labels a dorsally migrating population lying above the same line. (F) At $\mathrm{HHI} 8$, Lrrn2 is strongly expressed in BA2 but is essentially absent from BAI. Staining is also visible in scattered cells more dorsally in $r 2$ and $\mathrm{r} 4$, as well as in the ventral motor column (black arrows) and ventral midbrain. $(\mathrm{G}, \mathrm{H})$ Adjacent coronal sections through the branchial arch region at HHI8 shows Lrrn2 in the central core area of BA2 (red arrows). (I) Tbxl expression labels the mesodermal core of the branchial arches; staining in the BA2 core area is indicated by a red arrow. (J) CRABPI and (K) DIx2 are neural crest markers and show a peripheral crescent of staining in the branchial arches, unlike Lrrn2. Scale bars: $100 \mu \mathrm{m}(\mathrm{E}, \mathrm{I}-\mathrm{K})$. Courtesy of Robyn Quinlan and Anthony Graham.

ing for GFP (data not shown). Embryos were analysed 24 $\mathrm{h}$ following electroporation.

In situ hybridisation for Lrrn2 following overexpression of Shh throughout the left side of the hindbrain revealed upregulation of Lrrn2 only within $\mathrm{r} 4$ (Figure 3A-C; $\mathrm{n}=6$ ). Thus, although at later stages Lrrn2 is more widely expressed at low levels in a ventral domain throughout the $\mathrm{AP}$ axis of the neural tube, it is only strongly responsive to Shh signalling in $\mathrm{r} 4$.

To confirm that the region of Lrrn 2 upregulation in $\mathrm{r} 4$ corresponded to motor neurons, we used an Isl1 antibody, which labels all post-mitotic motor neurons [50]. As expected, we detected a dramatic expansion of the number of Isl $1^{+}$motor neurons throughout the hindbrain. A dorsal expansion of Isl $1^{+}$cells was seen on the electroporated side of the neural tube, but not on the control (unelectroporated) side (Figure 3B, B'). Sections through the hindbrain at the level of $\mathrm{r} 4$ demonstrate that the area of Lrrn2 upregulation co-labels with the Isl1 antibody (Figure 3C). Thus, while overexpression of Shh can lead to the induction of ectopic motor neurons all along the AP axis of the hindbrain, induction of Lrrn2 is restricted to those induced in $\mathrm{r} 4$. Moreover, it indicates that Lrrn2 is a specific marker of $\mathrm{r} 4$ motor neurons in the chick.

\section{Shh and Hoxbl co-operate to regulate the expression of Lrrn2}

Since Hoxb1 is known to confer $r 4$ identity, we next asked whether Lrrn2 could be a downstream target of Hoxb1.

An expression vector containing the mouse Hoxb1 coding region linked by an internal ribosomal entry site (IRES) sequence to GFP (pCA $\beta$-Hoxb1-IRES-eGFPm5; see Materials and methods) was electroporated into the developing hindbrain at HH9 and analysed 24 h later. In situ hybrid- isation with a mouse Hoxb1 probe and immunohistochemistry with an anti-GFP antibody confirmed coexpression. Ectopic Hoxb1 expression had no effect on Lrrn2 but expression in embryos that survived the electroporation procedure was always dorsal to the most ventral, Shh-expressing region of the hindbrain (data not shown). We reasoned that expression of Lrrn 2 might be dependent on Shh and, therefore, attempted to target Hoxb1 misexpression to the domain of endogenous Shh expression in the ventral hindbrain by modifying our electroporation technique to place the positive electrode underneath the neural tube. However, this region coincides with the location of the developing heart, and at the necessary voltages, electroporation at these stages resulted in terminal cardiac damage. We therefore co-electroporated pCA $\beta-H o x b 1-$ IRES-eGFPm5 with pXeX-Shh into more dorsal regions of the hindbrain. The combined expression of Shh and Hoxb1 in the hindbrain resulted in the upregulation of Lrrn2, but only in r1, r2, and r4 (Figure 4A-A"; n = 4). Despite the combined expression of both plasmids in $\mathrm{r} 3$ and r5, no induction of Lrrn2 was seen in these two rhombomeres. Therefore, Lrrn2 is a likely target of Hoxb1 and the co-expression of Hoxb1 with Shh is sufficient for its induction in $\mathrm{r} 1, \mathrm{r} 2$ and $\mathrm{r} 4$ neuroepithelium.

\section{Hoxbl can regulate the mesodermal component of Lrrn2 expression}

Hoxb1 is normally expressed in both the $\mathrm{r} 4$ neuroepithelium and $\mathrm{r} 4$ neural crest, but not in the mesoderm, so any effect on the mesodermal expression of Lrrn2 would be indirect. However, there is strong evidence to suggest the existence of interactive signalling between all three tissues during branchial arch patterning $[51,52]$. To see if the mesodermal expression of Lrrn2 in BA2 was responsive to the non-cell autonomous actions of Hoxb1, we overexpressed Hoxb1 in the hindbrain at HH10 and analysed embryos 48 h later. We saw no effect on the BA component of Lrrn2 expression when using pCA $\beta$-Hoxb1-IRES- 

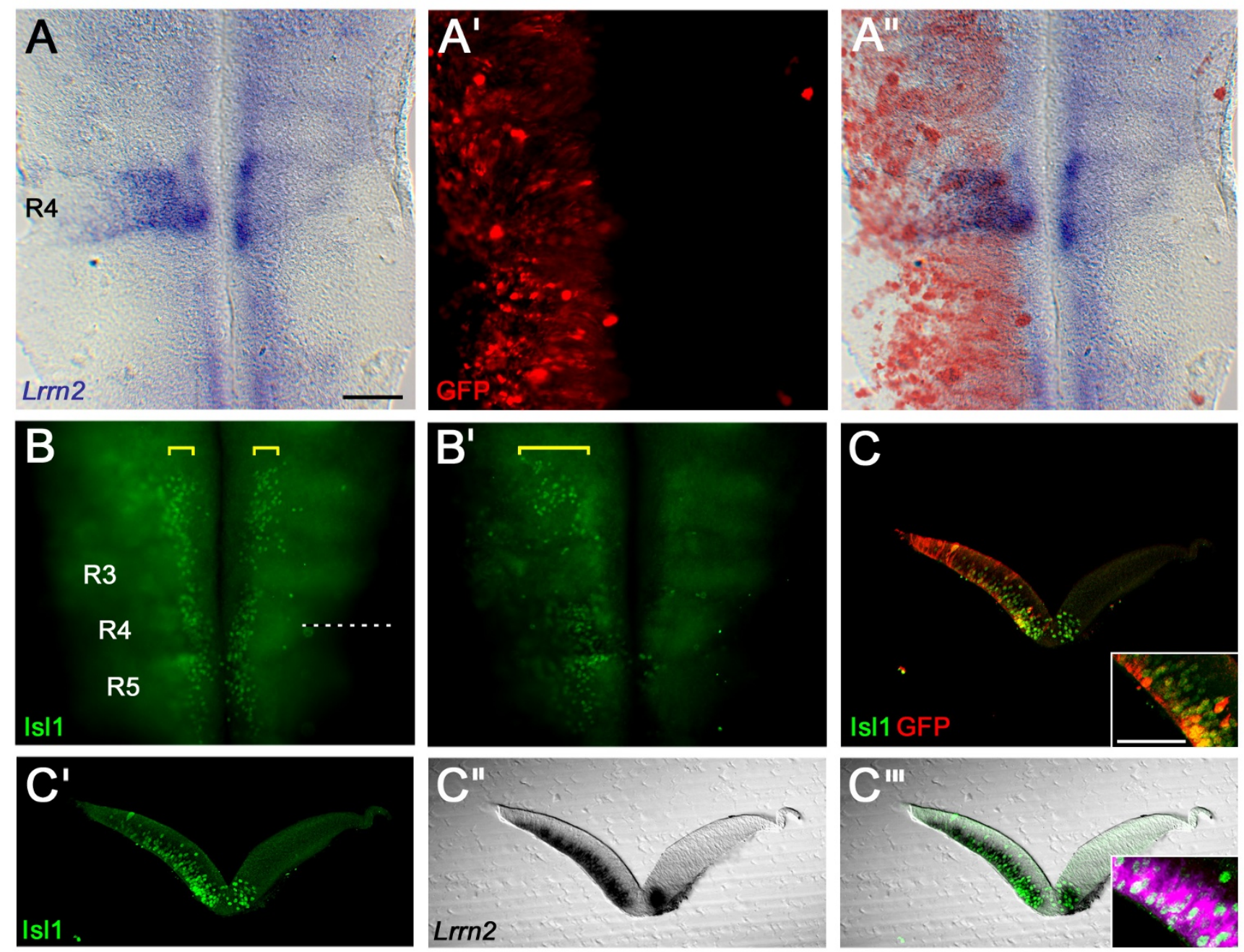

\section{Figure 3}

Shh upregulates Lrrn2 in rhombomere 4. (A-A") Co-electroporation of Shh and GFP results in overexpression throughout the left side of the hindbrain as visualised by anti-GFP labelling, reflecting a similar pattern of Shh misexpression (data not shown). This results in an upregulation of Lrrn2 expression only in $r 4$. (A) Lrrn2 expression, (A') GFP expression, (A") overlay. (B, B') The same embryo, following immunocytochemistry with anti-Isl I/2 antibody (green) to label motor neurons, showing the normal pattern of $|s| l / 2$ antibody staining in motor neurons lying adjacent to the floor plate (yellow brackets); (B) photo taken with focal plane set ventrally, and $\left(B^{\prime}\right)$ a more dorsal focal plane showing upregulation of IsII/2 throughout the left side of the hindbrain, as one would predict (expanded yellow bracket). Dashed line indicates the plane of section of (C-C"'). (C-C'") Transverse sections through the hindbrain at the level of $r 4$. (C) Overlay of IsII/2 in green and GFP in red, indicating unilateral Shh overexpression and induction of IsII/2 expression. Inset shows high power image. (C'-C'") The expansion of Lrrn2 expression can be seen to be confined to the mantle layer $\left(C^{\prime \prime}\right)$ and colocalises with upregulation of Islet I/2 (IsII/2 alone ( $\left.C^{\prime}\right)$; overlay with Lrrn2 (C"'); inset shows high power view with Lrrn2 expression pseudocoloured in magenta to more easily visualise overlap with Isl I/2 staining). Scale bar: $100 \mu \mathrm{m} ; 50 \mu \mathrm{m}$ (inset).

eGFPm5 for over-expression (not shown). However, this could have been a result of the significant dilution due to tissue growth that occurs over this period.

To obviate this possibility, we electroporated mouse Hoxb1 in the hindbrain region at HH9-11 using a plasmid encoding the retroviral vector $\operatorname{RCASBP}(\mathrm{B})-H_{0} x_{1}$ [6].
Embryos were analysed 2 days later for the expression of mouse Hoxb1 and Lrrn2, and sectioned on the coronal plane to visualise the cell populations of the branchial arches. Hoxb1 misexpression resulted in the induction of Lrrn2 in BA1 (Figure 4B, C; $\mathrm{n}=4$ ). Similarly to the endogenous situation in BA2, ectopic BA1 Lrrn2 expression was confined to the inner core of branchial arch mesenchyme 

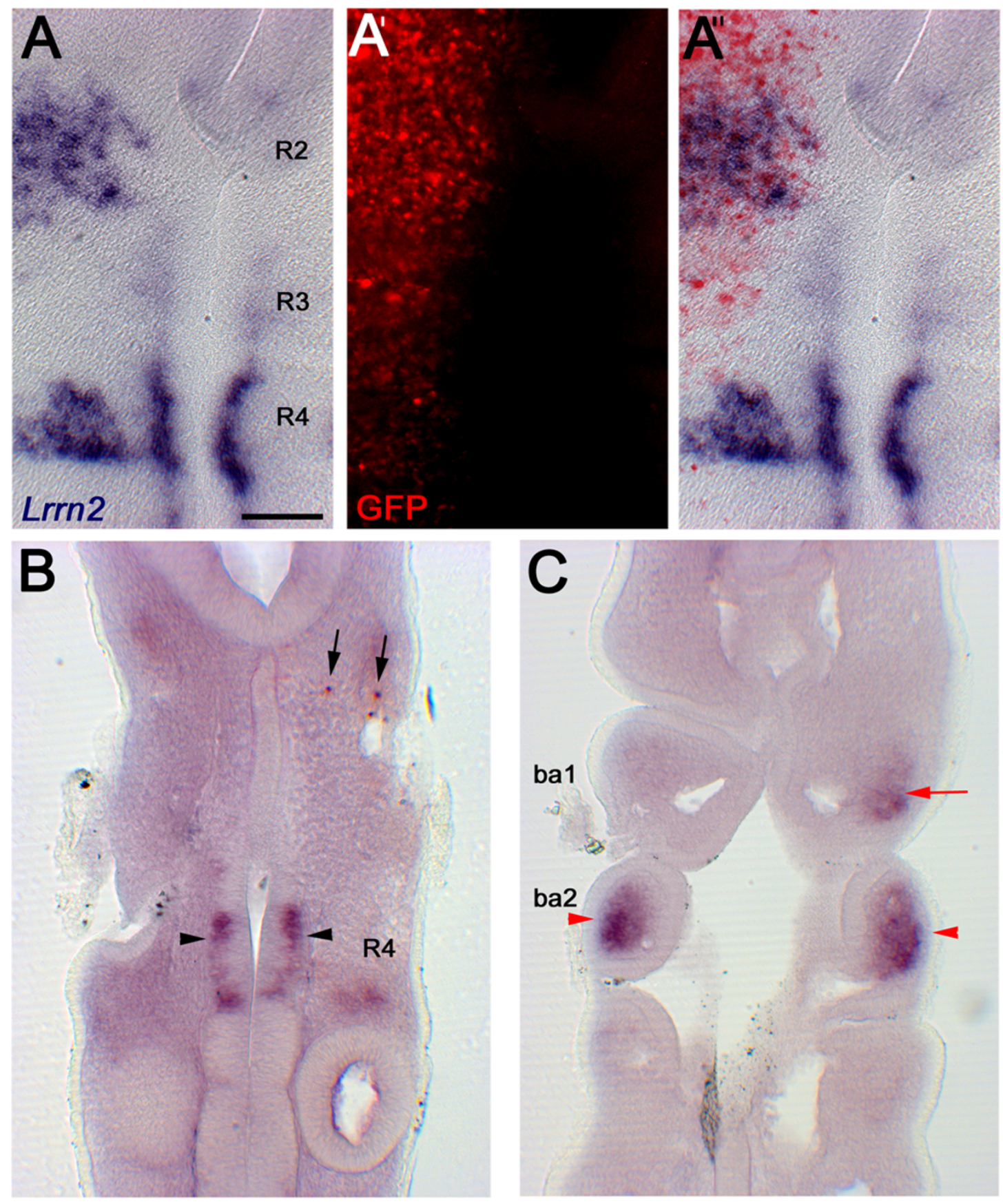

\section{Figure 4}

Hoxb I regulates Lrrn2 expression. (A-A") Overlay to show co-expression of ectopic Shh and Hoxbl and their effect on Lrrn2 expression in a flatmounted hindbrain, using an anti-GFP antibody to localise the region of misexpression. Widespread overexpression is seen throughout the hindbrain, but Lrrn2 is upregulated in rl, r2 and r4 only. (A) Brightfield view of Lrrn2 expression and ( $\left.A^{\prime}\right)$ fluorescence of anti-GFP antibody. (B-C) Coronal sections through an embryo electroporated with RCASBP(B)-mHoxb I at HHIO and processed 2 days later for Lrrn2 (dark purple) and mouse Hoxbl (red) expression by in situ hybridisation. (B) Section taken through ventral $r 4$ show endogenous expression of Lrrn2 in r4 (black arrowheads) and ectopic expression of mouse Hoxbl (black arrows). (C) Corresponding section taken more ventrally through the branchial arches of the same embryo shows upregulation of Lrrn2 expression in BAI mesoderm (red arrow) and endogenous expression in BA2 (red arrowheads). Scale bar: $100 \mu \mathrm{m}$. 
A
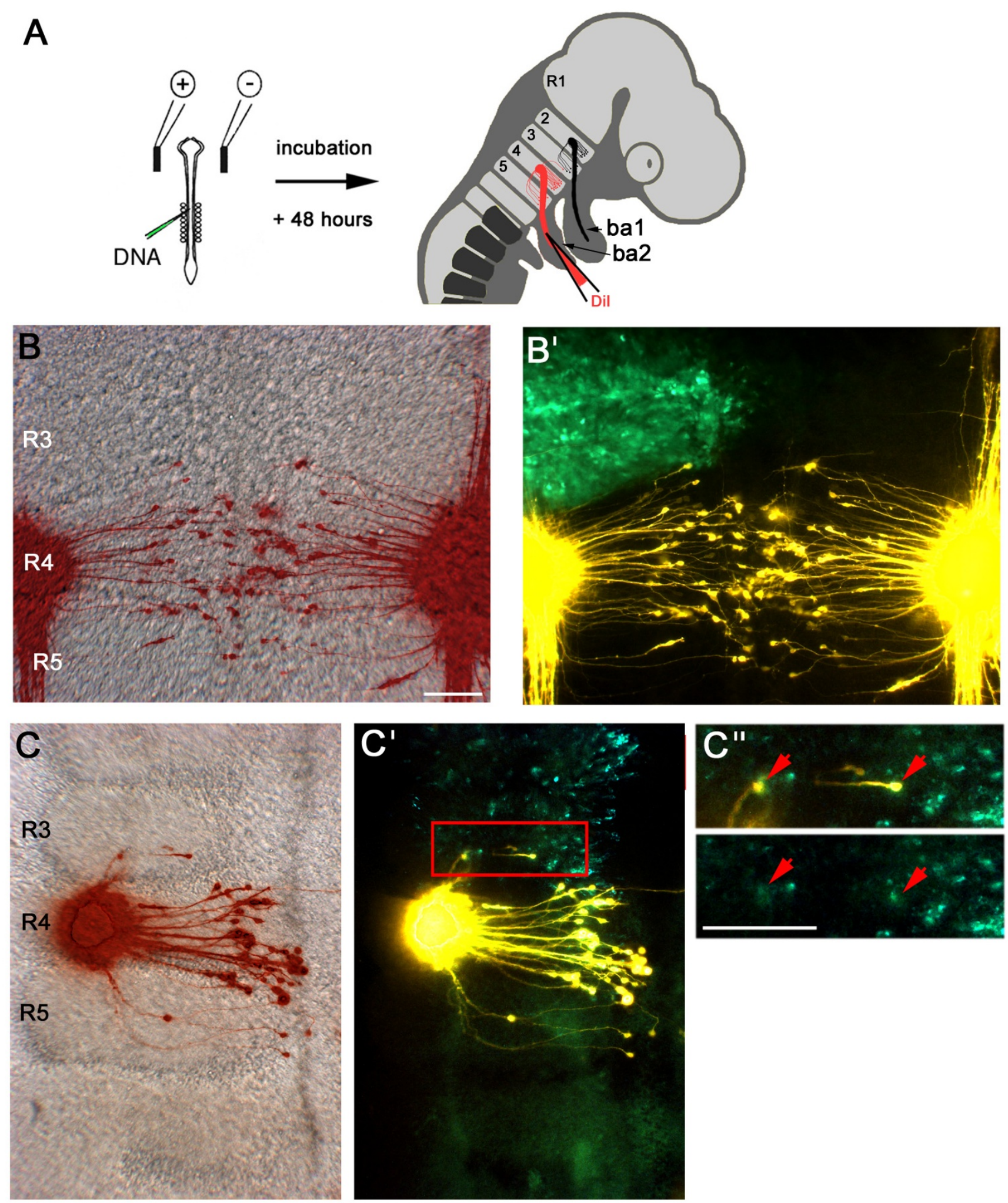

Figure 5 (see legend on next page) 
Figure 5 (see previous page)

Ectopic Lrrn2 can cause misrouting of axons. (A) Schematic to show experimental approach. On the left is shown a $\mathrm{HHIO}$ chick embryo with electrodes positioned on either side of the hindbrain. DNA is injected into the neural tube and following electroporation is expressed unilaterally on the side of the positive electrode. After $48 \mathrm{~h}$ embryos are harvested and the retrograde dye Dil is injected into BA2. Dye travels along axonal processes and labels the cell bodies from which they originate. (B, B') Flatmounted hindbrain from a control embryo electroporated with pCA $\beta$-eGFPm5 shows motor projections to BA2 labelled by retrograde Dil injection. (B) Overlay of artificially coloured Dil fluorescence (red) showing BA2 axons and a brightfield photograph of the hindbrain. ( $\left.B^{\prime}\right)$ Overlay showing strong GFP expression in $r 2$ and $r 3$ on the left side of the hindbrain. All axons projecting to BA2 clearly originate in $r 4$ and $r 5$ with no cell bodies lying anterior to the $r 3 / 4$ boundary. (C, C') Embryo with misexpression of Lrrn2-GFP in r2/3 shows several ectopic axons that project from cell bodies in r3 to BA2. (C") High power views of the boxed region in $\left(C^{\prime}\right)$ showing that the ectopic axons originate from Lrrn2-GFP ${ }^{+}$cells (red arrows).

Scale bars: $100 \mu \mathrm{m}$.

(Figure 4C; compare with BA1 staining of mesodermal marker Tbx1 in Figure 2I). These results indicate that Hoxb1 is able to ectopically upregulate the mesodermal expression of Lrrn2 in BA1.

\section{Mistargeting of r2/3 neurons expressing ectopic Lrrn2 to the second branchial arch}

The predicted secondary structure of Lrrn2 indicates that it is a single-pass transmembrane protein and a component of the plasma membrane, as we have previously shown for the closely related Lrrn 1 protein [32]. This is supported by biochemical and immunocytochemical data confirming it as a glycosylated protein and a component of the endoplasmic reticulum and Golgi complex [33]. A number of related proteins containing extracellular leucine-rich repeats have been shown to play an important role in cell adhesion and axon guidance [28-30,53-55]. A previous study has demonstrated that ectopic expression of Hoxb1 in basal $\mathrm{r} 2$ can result in the misprojection of $\mathrm{r} 2$ motor neurons [6] and we have now shown that Lrrn2 is downstream of Hoxb1. Since Lrrn2 is specifically expressed at a high level in $\mathrm{r} 4$ motor neurons and in their target tissue, the mesodermal pre-muscle mesenchyme of BA2, we postulated that it might function downstream of Hoxb1 in the guidance of $\mathrm{r} 4$ motor axons to their target pre-muscle region.

To test this hypothesis, we misexpressed Lrrn2 in r2/3 by electroporation and analysed the routing of axons to BA2 via retrograde tracing. A vector expressing the full-length Lrrn2 protein, fused at its intracellular carboxyl terminus to GFP (CAB-Lrrn2-eGFPm5; see Materials and methods), was electroporated unilaterally into the hindbrain at HH10-15. Embryos were harvested 2 days later, by which time motor projections have reached their targets in the branchial arches. Motor neuron axonal projections to BA2 were visualised by injecting the retrograde tracer DiI into BA2, so that all cell bodies with projections to BA2 are clearly labelled (Figure 5A).
Control electroporations using a GFP expression construct (pCA $\beta-e G F P m 5$ ) to misexpress GFP only in $\mathrm{r} 2 / 3$, did not result in any mis-targeted axons (Figure 5B, B'; $\mathrm{n}=15$ ). However, misexpression of Lrrn2-GFP in $\mathrm{r} 2 / 3$ over the same period resulted in a number of mistargeting events in embryos that showed intermediate-to-high levels of Lrrn2-GFP expression (Figure 5C-C"; $\mathrm{n}=4 / 5$; total 14 cells misrouted to BA2, 4 of 14 from r2, 10 of 14 from r3). This was, however, a rare event: of the four embryos with rerouted axons, only $2.5 \%$ (14 of 569) of Lrrn2-GFP+ cells in $\mathrm{r} 2 / 3$ showed mistargeting to BA2. Several embryos (five of five) with low-level expression (only a few scattered Lrrn2-GFP+ cells were visible) did not exhibit a rerouting phenotype. This phenotype may have been due to a community effect $[56,57]$. To investigate this further, we carefully examined the localization of Lrrn2-GFP-expressing cells in relation to misrouting. In total, approximately $30 \%$ of misrouted neurons (4 of 14 ) were surrounded by other Lrrn2-GFP+ cells and of the remaining 70\% (10 of 14), all showed at least one Lrrn2-GFP+ cell adjacent to the cell body of the misrouted neuron. These experiments indicate that ectopic Lrrn2 expression in r2/3 is sufficient to cause ectopic targeting of $\mathrm{r} 2 / 3$ axons to BA2 and, therefore, suggests that its normal role may be to participate in guiding facial motor axons to their target pre-muscle cells in BA2.

\section{Discussion}

In summary, Lrrn2 is expressed at a high level in postmitotic 44 motor neurons, and their target cells, the mesoderm-derived pre-muscle core of BA2. Hoxb1 and Shh co-operate to regulate Lrrn2 expression in $\mathrm{r} 4$ motor neurons, while Hoxb1 alone can upregulate Lrrn2 ectopically in the mesodermal core of BA1 via a non-cell autonomous mechanism. Furthermore, misexpression of Lrrn 2 in r2/3 can lead to axonal routing abnormalities, particularly ectopic projections from $\mathrm{r} 2 / 3$ neurons to BA2.

\section{Hoxbl and Shh regulate the expression of Lrrn2}

Hoxb1 acts as a selector gene to control r4 identity $[6,7,9]$ and thereby regulates, either directly or indirectly, a net- 
work of genes that all contribute to different aspects of $\mathrm{r} 4$ identity, including downstream transcriptional regulatory cascades and effectors of cellular behaviour. We have demonstrated that Lrrn2 is positively regulated by Hoxb1 and suggest that it represents one of these elusive effector genes. We have not yet addressed whether Hoxb1 and Shh act directly or indirectly on Lrrn2 expression and the molecular details underlying these interactions remain unknown. The Hoxb1 r4 autoregulatory enhancer has been well characterised in mouse and chick and consists of a number of conserved binding sites for Hoxb1, Pbx1 and Prep 1 [58-60]. We have conducted a preliminary search of the $\pm 10-\mathrm{kb}$ region flanking the chick Lrrn2 gene but have not identified any similar sequences that could represent Lrrn2 r4 regulatory elements. However, the chick genome sequence is incomplete and it remains possible that Hoxb1 could regulate Lrrn2 directly. Alternatively, given the regulation of expression in BA1 mesoderm is non-cell autonomous, it may act indirectly to regulate Lrrn2 in $\mathrm{r} 4$. There is only limited information available on downstream target genes of Hoxb1. Although Hoxb1 is known to directly regulate both itself [59], Hoxb2 [61] and Hoxa2 [62], previous work using electroporation to misexpress Hoxb1 ectopically in the chick hindbrain showed no upregulation of these genes [63], making these unlikely to act as intermediaries. GATA2 and GATA3 are transcription factors known to be expressed in $\mathrm{r} 4$ and regulated by Hoxb1, although it is not known if they represent direct targets $[6,17,18]$. Interestingly, uniform overexpression of Hoxb1 results in the upregulation of GATA2 only in r2 [18], which would be consistent with it acting as an intermediary to regulate Lrrn2.

Ectopic expression of Hoxb1 in the motor neuron progenitor domain of $\mathrm{r} 1$ is known to induce Isl 1 expression in this region, which is usually devoid of Isl1 staining [63]. This has been presumed to be due to a homeotic transformation of $r 1$ into an r4-like character [63]. However, it is not known if this is a direct effect and, as we have shown for Lrrn2, Isl1 induction probably requires Shh signalling since no Isl1 expression was seen outside the domain of endogenous Shh influence [63]. An example of a direct target of Hoxb1 is the paired-like homeodomain transcription factor Phox $2 b$, which is expressed in FBM neurons [19]. However, as both Isl1 and Phox 2b are strongly expressed throughout the AP axis of the hindbrain and do not show r4-specific expression, they cannot mediate $\mathrm{r} 4$ specificity of Lrrn2 expression.

Although the regulation of Lrrn2 by Hoxb1 may be indirect, it represents a strong candidate for a downstream effector gene, of which very few have been described. A recent microarray screen in zebrafish searching for downstream targets of $z f H o x b 1 a$ has identified 12 genes, including prickle $1 b$, which is required for FBM neuron migration
[20]. It is not yet known whether any or all of these zebrafish Hoxb1a targets are direct or indirect [20] but, like Lrrn2, they critically display $\mathrm{r} 4$ specificity and are, therefore, likely to be involved in generating $\mathrm{r} 4$-specific identity and cell behaviours.

Similarly, regulation of Lrrn2 by Shh could be at the level of its transcriptional effectors, the Gli family members [64-66], or further downstream. For example, Nkx2.2 is expressed in the appropriate branchiomotor progenitor domain and, although it is rapidly lost from post-mitotic neurons, could be involved in the induction of Lrrn2 expression [11,15]. The expression domain of Lrrn 2 in $\mathrm{r} 4$ corresponds closely to those of Isl1/2 (Figure 3) [67] and Phox $2 b$ [68]. These are, therefore, candidate intermediaries for the action of Shh on Lrrn2. Both Isl1/2 and Phox2b are critical for the development of FBM neurons. Isl1 is an early marker for motor neurons [50] and is required for motor neuron generation [69]. Loss of Phox $2 b$ leads to a failure in axon extension and migration of FBM neurons followed by extensive cell death $[70,71]$.

The ectopic expression of Hoxb1 alone was able to upregulate the expression of Lrrn2 in BA1 mesoderm. This suggests that the endogenous BA2 expression of Lrrn2 may be Hoxb1-dependent. Since Hoxb1 is not normally expressed in the branchial arches, and only in the neurogenic r4-derived neural crest $[2,72]$, any normal regulation of the mesodermal expression of Lrrn 2 must be indirect and involve an unknown secreted signal, with a mechanism that may be distinct from that operating in $\mathrm{r} 4$ motor neurons. This is consistent with the absence of ectopic Hoxb1 in the cells expressing ectopic Lrrn2. It has been shown that the cranial neural crest, mesoderm and their surrounding epithelial tissues signal important patterning information to each other, suggesting close interdependence in arch patterning [51,52,73-77]. Furthermore, experiments using chimaeric embryos containing a mixture of wild-type and Hoxb1\% cells have demonstrated that Hoxb1 is required in the neural crest prior to delamination to establish and maintain the facial motor neuron circuit [78]. We hypothesise that ectopic Hoxb1 expressed in $\mathrm{r} 2$ neural crest may induce homeotic changes in BA1, including induction of BA2 mesodermal markers like Lrrn2.

\section{Lack of up-regulation of Lrrn2 by Hoxbl and Shh in r3 or r5}

The combination of Hoxb1 and Shh was not able to induce Lrrn 2 expression in $\mathrm{r} 3$ and $\mathrm{r} 5$. It has been shown that in transgenic mice that express Hoxb1 ubiquitously, GATA2 is ectopically upregulated only in $\mathrm{r} 2$ [18], while previous data from our laboratory have shown that Hoxb1 misexpression throughout the hindbrain can induce strong, r4-like expression of the immunoglobulin 
superfamily cell surface glycoprotein BEN in r2 but not in r3 or r5 [6]. Moreover, while in some embryos r2 motor axons projected inappropriately to BA2, almost all Hoxb1-expressing r3 motor neurons retained their correct projection to BA1 [6]. It seems, therefore, that $\mathrm{r} 3$ motor neurons are refractory to the effects of ectopic Hoxb1 expression. Our results provide the possible explanation that this could be due to a lack of induction of Lrrn2, which would act as a guidance factor for BA2-targeted axons. It is possible that $\mathrm{r} 3$ and $\mathrm{r} 5$ can exert repressive effects downstream of Hoxb1 by acting on its target genes. A potential candidate for such an effect is the zinc finger transcription factor Krox20, which is expressed in r3 and r5 from early stages. It is clear that there are fundamental differences between odd and even numbered rhombomeres. The identification of Lrrn2 as a downstream target of Hoxb1 makes it a useful tool to further dissect the regulation of this odd-even periodicity.

Ectopic Lrrn2 in r2/3 can lead to rerouting of axons to BA2 While misexpression of Lrrn 2 in $\mathrm{r} 2 / 3$ resulted in the misprojection of some axons to the $\mathrm{r} 4$ exit point and BA2, this was a rare event and we did not observe the dramatic rerouting seen by Bell et al. [6] when misexpressing Hoxb1 in r2. This may be due to a number of factors associated with the different methodologies used. Electroporation frequently leads to lower levels and a mosaic distribution of expression compared to viral misexpression. In support of this idea, other investigators have commented on the necessity for 'very efficient electroporation' [79], where the operation of dominant community effects may reinforce the status quo $[57,80]$. Alternatively, the developmental stage at which the experiments were carried out may have affected the outcome. Retroviral Hoxb1-misexpression by Bell et al. was carried out at HH3 while our experiments were performed at HH10-14. It is possible that later in development cells have become committed to a specific fate that cannot be altered. For example, r5 somatic motor neurons become committed to their fate between HH9 and HH10 [81]. Consistent with this, electroporation of Hoxb1-IRES-GFP at HH10-14 into r2/3 did not lead to any routing abnormalities $(n=16$, data not shown). Unfortunately, attempts to use either higher voltages or earlier stages were not compatible with survival. It is also likely that other guidance molecules are involved, particularly at interim decision points in outgrowth and pathfinding, such as to find the correct exit point from the hindbrain [82]. The absence of these in Lrrn2 misexpressing cells may have contributed to the low incidence of rerouting.

\section{Lrrn2 and neuromuscular targeting: a conserved role from Drosophila?}

One of the most striking aspects of Lrrn2 expression is the correlation between a particular subset of hindbrain motor neurons, the facial branchiomotor neurons of $\mathrm{r} 4$, and their prospective muscle targets, the core mesoderm cells of BA2. Although cell adhesion/recognition molecules that display such a correspondence have been identified in invertebrates, very few have been found in vertebrates. In a tantalising parallel, one of the closest Drosophila homologues to the Lrrn proteins is Caps, which is expressed on a subset of motor neurons and their muscle targets, and is known to play a role in regulating target specificity of motor neurons [30,31]. In caps mutants, axon targeting for one of these matching pairs is abnormal. Pan-muscle expression of Caps results in the muscle 12 motor neurons forming ectopic synapses on a nearby muscle, while pan-neural expression of Caps leads to pathfinding errors in the same motor neurons [30,83]. This may in part be mediated by a sensing function of Caps expressed on muscle filopodia to enable synaptic matching [31]. Caps has also been shown to mediate specific axon-target interactions in the Drosophila visual system, where it is expressed in R8 photoreceptors and their target layer, and regulates this layer-specific targeting [55]. Another closely related LRR molecule, Connectin, plays a similar role in another set of motor neurons and their muscle targets $[28,29,54]$, and has been identified as one of the few known cell adhesion molecules to be directly regulated by a member of the Hox/HOM-C complex, Ubx $[84,85]$.

Cues acting on generic features of motor neuron development have been identified [21-23,86]. However, knowledge about specific factors that endow individual identity to a motor neuron and specificity for its target muscle group is lacking. It is tempting to speculate that Lrrn2 might function in an analogous manner to Drosophila Caps in the specific targeting of facial branchiomotor neurons to the muscles of the BA2. To determine if this is the case, an experimental design would be required that would drive Lrrn 2 expression in $\mathrm{r} 2$ motor neurons from an early developmental stage to look for rerouting, and, in a complementary approach, expression would be driven in BA1 mesoderm to see if r4 FBMs ectopically synapsed on to BA1 muscles. However, this is not yet feasible in the chick with current techniques.

Lrrn2 is also strongly expressed in a number of other sites in the developing chick embryo, such as the region on the right-hand side of Hensen's node and the ventral midbrain, where its role remains unknown. If Lrrn2 has a role specific to $\mathrm{r} 4$, could other related proteins serve similar functions in different regions of the neuraxis, perhaps downstream of other Hox genes? Lrrn2 is part of a threemember gene family in chick and mouse [32,33], but neither Lrrn1 [32] nor Lrrn3 (unpublished data) show expression patterns in the chick obviously consistent with this. However, there is a very large extended family of closely 
related genes (in the fibronectin leucine-rich transmembrane (FLRT) family, leucine-rich transmembrane family (LRRTM/LRTM) and LINGO/LRRN6/LERN family [8790]), members of which might well perform similar roles in other cell types and species.

\section{Conclusion}

We have identified a novel cell surface receptor in the chick, Lrrn2, which is specifically expressed by $\mathrm{r} 4$ motor neurons and their prospective target tissue, the mesodermal pre-muscle core of BA2. Its expression in $\mathrm{r} 4$ motor neurons is regulated by Hoxb1, in co-operation with the signalling molecule Shh. Misexpression of Lrrn2 in r2/3 results in ectopic axonal projections to the $\mathrm{r} 4$ exit point and BA2, indicating that Lrrn2 may be a candidate for regulating specific motor axonal targeting in the vertebrate hindbrain.

\section{Materials and methods Chick methods}

Chicken eggs (Rhode Island Red) were incubated at $38^{\circ} \mathrm{C}$ in 40 to $50 \%$ humidity until the appropriate stage was reached. Embryos were staged according to Hamburger and Hamilton [91].

\section{In ovo electroporation}

Chick eggs were incubated until the appropriate stage was reached. Electrodes were made from silver wire (diameter $0.5 \mathrm{~mm})$, platinum-iridium wire $(80: 20 \mathrm{mix}$, diameter 0.25 or $0.5 \mathrm{~mm}$ ) or tungsten wire (diameter $0.125 \mathrm{~mm}$ ) and placed at the desired position relative to the embryo. DNA at 0.5 to $1.0 \mu \mathrm{g} / \mu \mathrm{l}$ in water containing $0.1 \%$ Fast Green to aid visualization was pressure injected into the lumen of the neural tube using a glass capillary micropipette. Square wave pulses of 8 to $20 \mathrm{~V}$ ( 1 to 6 pulses of 50 $\mathrm{ms}$ ) were delivered to the tissue using an Intracept TSS10 Dual Pulse isolated stimulator (Intracel, Royston, Herts, $\mathrm{UK}$ ). The electrodes were removed and a few drops of Tyrode's solution (containing $137 \mathrm{mM} \mathrm{NaCl}, 2.7 \mathrm{mM}$ $\mathrm{KCl}, 0.32 \mathrm{mM} \mathrm{NaH}_{2} \mathrm{PO}_{4} .2 \mathrm{H}_{2} \mathrm{O}, 2.4 \mathrm{mM} \mathrm{CaCl}_{2}, 1.0 \mathrm{mM}$ $\mathrm{MgCl}_{2}, 5.5 \mathrm{mM}$ glucose) were added. Eggs were resealed and returned to the incubator for 24 to $48 \mathrm{~h}$ before harvesting.

To generate the Hoxb1-IRES-GFP expression vector, the coding sequence of mouse Hoxb1 was excised from RCAS(BP)B-Hoxb1 [6] as a ClaI fragment and cloned into the vector CA-IRES eGFPm5. This consists of the hybrid cytomegalovirus enhancer-chick $\beta$ actin promoter vector pCAGGS $[92,93]$ containing the encephalocardiomyopathy virus (ECMV) IRES and a modified polylinker (A Hunter and J Gilthorpe, details available upon request). The correct insert orientation was verified by restriction endonuclease digestion. The CAB-Lrrn2-eGFPm5 fusion vector was generated by PCR amplification of the Lrrn2 coding region, without the stop codon, using the plasmid template used to generate the Lrrn2 in situ probe (see below) and cloning into the pCR4-TOPO vector (Invitrogen, Carlsbad, CA, US). Following DNA sequencing to verify the sequence of the insert, it was cloned into pCAeGFPm5 (details available upon request). Other expression vectors used were: pCA $\beta-e G F P m 5$ [49], pXEX-cShh (gift of C Ragsdale) [48], RCASBP(B)-mHoxb1 [6].

\section{Retrograde labelling of axons with Dil}

Embryos were fixed with 4\% paraformaldehyde (PFA) and pinned down in a Sylgard-coated dish (Dow Corning, Midland, MI, US). DiI (1,1'-didodecyl-3,3,3',3'-tetramethylindocarbocyanine perchlorate; Invitrogen) was pressure injected via a glass capillary micropipette into the dorsalproximal region of the second branchial arch. Embryos were kept in the dark at room temperature for 1 week in PFA and then examined under a fluorescence dissecting microscope before flatmounting hindbrains.

\section{In situ hybridisation}

Chick embryos were fixed overnight at $4{ }^{\circ} \mathrm{C}$ in PFA. Single and double in situ hybridisations were performed as described previously [32] except that hybridisation with the Lrrn2 probe was carried out at $72^{\circ} \mathrm{C}$. Chick Lrrn2 (gift of F Murray, Roslin Institute, Roslin, Edinburgh) [GenBank:AL588402] was linearized with SalI and transcribed with SP6 RNA polymerase (Roche Applied Science, Burgess Hill, UK) to generate an antisense probe. Additional plasmid templates were used to generate antisense riboprobes as follows: chick Shh (SalI-SP6; gift of T Lints); chick Hoxb1 (XbaI-T7; gift of V Prince), mouse Hoxb1 (HindIII-T7; gift of R Krumlauf).

\section{Wholemount immunohistochemistry}

Following in situ hybridization, embryos were washed and blocked in phosphate-buffered saline (PBS) containing $1 \%$ new born calf serum for $3 \times 45$ minutes at room temperature. Embryos were incubated in primary antibody (diluted in PBS $/ 1 \%$ new born calf serum containing $0.1 \%$ tritonX-100 (PBST) for 2 to 3 days at $4{ }^{\circ} \mathrm{C}$ and then washed three times in PBST for 60 minutes each at $4{ }^{\circ} \mathrm{C}$. They were then transferred into fluorescently conjugated secondary antibody (Alexa Fluor ${ }^{\circledast}$, Invitrogen; goat antirabbit or anti-mouse depending on primary), diluted $1: 200$ in PBS/ $1 \%$ newborn goat serum $/ 0.1 \%$ tritonX-100, and incubated overnight at $4{ }^{\circ} \mathrm{C}$. Embryos were washed three times for 45 minutes each at room temperature. Primary antibodies used were rabbit anti-GFP (Invitrogen) at 1:1,000 and mouse anti-Islet-1 (4D5, Developmental Studies Hybridoma Bank) at 1:10.

\section{Flatmounting and photography}

Embryos were cleared in $80 \%(\mathrm{v} / \mathrm{v})$ glycerol prior to digital photography of wholemounts (Olympus DP70 CCD 
camera). Some specimens were dissected and flatmounted in glycerol under a No. 1.5 coverslip. Vibratome (Leica VT 1000S) sections were cut at $40 \mu \mathrm{m}$ after embedding tissue in $20 \%(\mathrm{w} / \mathrm{v})$ gelatine/PBS. Following infiltration in gelatine at $65^{\circ} \mathrm{C}$ for 1 to $2 \mathrm{~h}$, tissue was embedded and then post-fixed in PFA. Flatmounts and sections were viewed on a Zeiss Axiophot microscope and digitally photographed with a Zeiss Axiocam. Confocal images were taken on an Olympus Fluoview FV500 laser scanning confocal microscope using Fluoview software.

\section{Abbreviations}

AP: anterior-posterior; BA: branchial arch; Caps: Capricious; CNS: central nervous system; DV: dorsal-ventral; FBM: facial branchiomotor; GFP: green fluorescent protein; HH: Hamburger and Hamilton stage; IRES: internal ribosomal entry site; Isl: Islet; Lrrn: leucine-rich repeat neuronal; PBS: phosphate-buffered saline; PFA: paraformaldehyde; r: rhombomere; Shh: Sonic hedgehog; VA: vestibular-acoustic.

\section{Competing interests}

The authors declare that they have no competing interests.

\section{Authors' contributions}

LCA participated in the conception and design of the study, performed the experiments and drafted the manuscript. JDG generated the CAB-Lrrn2-eGFPm5 construct. AL and JDG participated in the conception and design of the study and helped draft the manuscript. All authors read and approved the final manuscript.

\section{Acknowledgements}

We would like to thank Frazer Murray (Roslin Institute) for the chick Lrrn2 plasmid, Anthony Graham and Robyn Quinlan for Tbx I, CRABPI, DIx2 and $R X R$ in situ hybridization pictures, members of the Lumsden lab for helpful discussions and Dr Carol Irving for critical reading of the manuscript. The 5EI monoclonal antibody developed by Professor TM Jessell was obtained from the Developmental Studies Hybridoma Bank developed under the auspices of the NICHD and maintained by the University of lowa, Department of Biological Sciences, lowa City, IA 52242, USA. This work was funded by the Medical Research Council.

\section{References}

I. Lumsden A, Krumlauf R: Patterning the vertebrate neuraxis. Science 1996, 274: I I09-III5.

2. Hunt $P$, Gulisano $M$, Cook $M$, Sham $M H$, Faiella $A$, Wilkinson $D$, Boncinelli E, Krumlauf R: A distinct Hox code for the branchial region of the vertebrate head. Nature I991, 353:86I-864.

3. Murphy P, Davidson DR, Hill RE: Segment-specific expression of a homoeobox-containing gene in the mouse hindbrain. Nature 1989, 341:156-159.

4. Wilkinson DG, Bhatt S, Cook M, Boncinelli E, Krumlauf R: Segmental expression of Hox-2 homoeobox-containing genes in the developing mouse hindbrain. Nature 1989, 341:405-409.

5. Alexandre D, Clarke JD, Oxtoby E, Yan YL, Jowett T, Holder N: Ectopic expression of Hoxa- $I$ in the zebrafish alters the fate of the mandibular arch neural crest and phenocopies a retinoic acid-induced phenotype. Development 1996, I 22:735-746.
6. Bell E, Wingate RJ, Lumsden A: Homeotic transformation of rhombomere identity after localized Hoxb I misexpression. Science 1999, 284:2 I68-2I7I.

7. Goddard JM, Rossel M, Manley NR, Capecchi MR: Mice with targeted disruption of Hoxb-I fail to form the motor nucleus of the VIIth nerve. Development 1996, I 22:3217-3228.

8. Krumlauf R: Hox genes in vertebrate development. Cell I994, 78: $|9|-20 \mid$.

9. Studer M, Lumsden A, Ariza-McNaughton L, Bradley A, Krumlauf R: Altered segmental identity and abnormal migration of motor neurons in mice lacking Hoxb-I. Nature 1996, 384:630-634.

10. Zhang M, Kim HJ, Marshall H, Gendron-Maguire M, Lucas DA, Baron A, Gudas LJ, Gridley T, Krumlauf R, Grippo JF: Ectopic Hoxa-I induces rhombomere transformation in mouse hindbrain. Development 1994, I 20:2431-2442.

II. Ericson J, Rashbass P, Schedl A, Brenner-Morton S, Kawakami A, van Heyningen V, Jessell TM, Briscoe J: Pax6 controls progenitor cell identity and neuronal fate in response to graded Shh signaling. Cell 1997, 90:169-180.

12. Marti E, Bumcrot DA, Takada R, McMahon AP: Requirement of I9K form of Sonic hedgehog for induction of distinct ventral cell types in CNS explants. Nature 1995, 375:322-325.

13. Roelink H, Porter JA, Chiang C, Tanabe Y, Chang DT, Beachy PA, Jessell TM: Floor plate and motor neuron induction by different concentrations of the amino-terminal cleavage product of sonic hedgehog autoproteolysis. Cell 1995, 81:445-455.

14. Briscoe J, Pierani A, Jessell TM, Ericson J: A homeodomain protein code specifies progenitor cell identity and neuronal fate in the ventral neural tube. Cell 2000, I $01: 435-445$.

I5. Briscoe J, Sussel L, Serup P, Hartigan-O'Connor D, Jessell TM, Rubenstein JL, Ericson J: Homeobox gene Nkx2.2 and specification of neuronal identity by graded Sonic hedgehog signalling. Nature 1999, 398:622-627.

16. Studer M, Popperl H, Marshall H, Kuroiwa A, Krumlauf R: Role of a conserved retinoic acid response element in rhombomere restriction of Hoxb-I. Science 1994, 265: I728-I732.

17. Nardelli J, Thiesson D, Fujiwara Y, Tsai FY, Orkin SH: Expression and genetic interaction of transcription factors GATA-2 and GATA-3 during development of the mouse central nervous system. Dev Biol 1999, 21 0:305-321.

18. Pata I, Studer M, van Doorninck JH, Briscoe J, Kuuse S, Engel JD, Grosveld F, Karis A: The transcription factor GATA3 is a downstream effector of Hoxb I specification in rhombomere 4. Development 1999, I 26:5523-5531.

19. Samad OA, Geisen MJ, Caronia G, Varlet I, Zappavigna V, Ericson J, Goridis C, Rijli FM: Integration of anteroposterior and dorsoventral regulation of $\mathbf{P h o x} 2 \mathrm{~b}$ transcription in cranial motoneuron progenitors by homeodomain proteins. Development 2004, | 3 1:407|-4083.

20. Rohrschneider MR, Elsen GE, Prince VE: Zebrafish Hoxb I a regulates multiple downstream genes including prickle I b. Dev Biol 2007, 309:358-372.

21. Caton A, Hacker A, Naeem A, Livet J, Maina F, Bladt F, Klein R, Birchmeier C, Guthrie S: The branchial arches and HGF are growthpromoting and chemoattractant for cranial motor axons. Development 2000, I27:1751-1766.

22. Lieberam I, Agalliu D, Nagasawa T, Ericson J, Jessell TM: A Cxcl I 2CXCR4 chemokine signaling pathway defines the initial trajectory of mammalian motor axons. Neuron 2005, 47:667-679.

23. Varela-Echavarria A, Tucker A, Puschel AW, Guthrie S: Motor axon subpopulations respond differentially to the chemorepellents netrin-I and semaphorin D. Neuron 1997, 1 8: 193-207.

24. Ebens A, Brose K, Leonardo ED, Hanson MG Jr, Bladt F, Birchmeier C, Barres BA, Tessier-Lavigne M: Hepatocyte growth factor/scatter factor is an axonal chemoattractant and a neurotrophic factor for spinal motor neurons. Neuron 1996, I 7: I I57-I I 72.

25. Jacob J, Guthrie S: Facial visceral motor neurons display specific rhombomere origin and axon pathfinding behavior in the chick. J Neurosci 2000, 20:7664-767I.

26. Goodman CS: The likeness of being: phylogenetically conserved molecular mechanisms of growth cone guidance. Cell 1994, 78:353-356.

27. Tessier-Lavigne M, Goodman CS: The molecular biology of axon guidance. Science 1996, 274: I I23-II33. 
28. Nose A, Mahajan VB, Goodman CS: Connectin: a homophilic cell adhesion molecule expressed on a subset of muscles and the motoneurons that innervate them in Drosophila. Cell 1992, 70:553-567.

29. Nose A, Umeda T, Takeichi M: Neuromuscular target recognition by a homophilic interaction of connectin cell adhesion molecules in Drosophila. Development I997, I 24: |433- I44I.

30. Shishido E, Takeichi M, Nose A: Drosophila synapse formation: regulation by transmembrane protein with Leu-rich repeats, CAPRICIOUS. Science 1998, 280:2||8-2|2|.

31. Kohsaka $H$, Nose $A$ : Target recognition at the tips of postsynaptic filopodia: accumulation and function of Capricious. Development 2009, I36:1 I27-II35.

32. Andreae LC, Peukert D, Lumsden A, Gilthorpe JD: Analysis of Lrrn I expression and its relationship to neuromeric boundaries during chick neural development. Neural Dev 2007, 2:22.

33. Haines BP, Gupta R, Jones CM, Summerbell D, Rigby PW: The NLRR gene family and mouse development: Modified differential display PCR identifies NLRR-I as a gene expressed in early somitic myoblasts. Dev Biol 2005, 28I:145-159.

34. Taguchi A, Wanaka A, Mori T, Matsumoto K, Imai Y, Tagaki T, Tohyama M: Molecular cloning of novel leucine-rich repeat proteins and their expression in the developing mouse nervous system. Brain Res Mol Brain Res 1996, 35:3 I-40.

35. Taniguchi $H$, Tohyama $M$, Takagi $T$ : Cloning and expression of a novel gene for a protein with leucine-rich repeats in the developing mouse nervous system. Brain Res Mol Brain Res 1996, 36:45-52.

36. Sundin $\mathrm{OH}$, Eichele $\mathrm{G}$ : A homeo domain protein reveals the metameric nature of the developing chick hindbrain. Genes Dev 1990, 4: 1267-1276.

37. Lumsden A, Keynes R: Segmental patterns of neuronal development in the chick hindbrain. Nature 1989, 337:424-428.

38. Briscoe J, Ericson J: Specification of neuronal fates in the ventral neural tube. Curr Opin Neurobiol 200I, I I:43-49.

39. Simon H, Guthrie S, Lumsden A: Regulation of SCI/DM-GRASP during the migration of motor neurons in the chick embryo brain stem. J Neurobiol 1994, 25: | | 29- I | 43.

40. Simon H, Lumsden A: Rhombomere-specific origin of the contralateral vestibulo-acoustic efferent neurons and their migration across the embryonic midline. Neuron 1993, II:209-220.

4I. Noden DM: Cell movements and control of patterned tissue assembly during craniofacial development. J Craniofac Genet Dev Biol 1991, II:192-213.

42. Rowe A, Eager NS, Brickell PM: A member of the RXR nuclear receptor family is expressed in neural-crest-derived cells of the developing chick peripheral nervous system. Development |991, I II:77|-778.

43. Vitelli F, Morishima M, Taddei I, Lindsay EA, Baldini A: Tbx I mutation causes multiple cardiovascular defects and disrupts neural crest and cranial nerve migratory pathways. Hum Mol Genet 2002, I I:915-922.

44. Zhang Z, Huynh T, Baldini A: Mesodermal expression of TbxI is necessary and sufficient for pharyngeal arch and cardiac outflow tract development. Development 2006, I33:3587-3595.

45. Maden M, Hunt $P$, Eriksson $U$, Kuroiwa $A$, Krumlauf R, Summerbell $D$ : Retinoic acid-binding protein, rhombomeres and the neural crest. Development 1991, I I I:35-43.

46. Bulfone A, Kim HJ, Puelles L, Porteus MH, Grippo JF, Rubenstein JL: The mouse DIx-2 (Tes-I) gene is expressed in spatially restricted domains of the forebrain, face and limbs in midgestation mouse embryos. Mech Dev 1993, 40:129-140.

47. Qiu M, Bulfone A, Martinez S, Meneses IJ, Shimamura K, Pedersen RA, Rubenstein JL: Null mutation of Dlx-2 results in abnormal morphogenesis of proximal first and second branchial arch derivatives and abnormal differentiation in the forebrain. Genes Dev 1995, 9:2523-2538.

48. Agarwala S, Sanders TA, Ragsdale CW: Sonic hedgehog control of size and shape in midbrain pattern formation. Science 200I, 291:2147-2150.

49. Yaneza M, Gilthorpe JD, Lumsden A, Tucker AS: No evidence for ventrally migrating neural tube cells from the mid- and hindbrain. Dev Dyn 2002, 223:163-167.
50. Ericson J, Thor S, Edlund T, Jessell TM, Yamada T: Early stages of motor neuron differentiation revealed by expression of homeobox gene Islet-I. Science 1992, 256: I 555-1560.

5I. Santagati F, Rijli FM: Cranial neural crest and the building of the vertebrate head. Nat Rev Neurosci 2003, 4:806-818.

52. Trainor PA, Krumlauf R: Hox genes, neural crest cells and branchial arch patterning. Curr Opin Cell Biol 200I, 1 3:698-705.

53. Karaulanov EE, Bottcher RT, Niehrs C: A role for fibronectin-leucine-rich transmembrane cell-surface proteins in homotypic cell adhesion. EMBO Rep 2006, 7:283-290.

54. Nose A, Takeichi M, Goodman CS: Ectopic expression of connectin reveals a repulsive function during growth cone guidance and synapse formation. Neuron 1994, 13:525-539.

55. Shinza-Kameda M, Takasu E, Sakurai K, Hayashi S, Nose A: Regulation of layer-specific targeting by reciprocal expression of a cell adhesion molecule, capricious. Neuron 2006, 49:205-2I3.

56. Cooper KL, Leisenring WM, Moens CB: Autonomous and nonautonomous functions for $\mathrm{Hox} / \mathrm{Pbx}$ in branchiomotor neuron development. Dev Biol 2003, 253:200-2/3.

57. Gurdon JB, Lemaire $P$, Kato K: Community effects and related phenomena in development. Cell 1993, 75:831-834.

58. Chan SK, Mann RS: A structural model for a homeotic proteinextradenticle-DNA complex accounts for the choice of HOX protein in the heterodimer. Proc Natl Acad Sci USA 1996, 93:5223-5228.

59. Popperl H, Bienz M, Studer M, Chan SK, Aparicio S, Brenner S, Mann RS, Krumlauf R: Segmental expression of Hoxb-I is controlled by a highly conserved autoregulatory loop dependent upon exd/pbx. Cell 1995, 81:1031-1042.

60. Ferretti E, Cambronero F, Tumpel S, Longobardi E, Wiedemann LM, Blasi F, Krumlauf R: Hoxbl enhancer and control of rhombomere 4 expression: complex interplay between PREPIPBXI-HOXB I binding sites. Mol Cell Biol 2005, 25:854I-8552.

6I. Maconochie MK, Nonchev S, Studer M, Chan SK, Popperl H, Sham $\mathrm{MH}$, Mann RS, Krumlauf R: Cross-regulation in the mouse HoxB complex: the expression of Hoxb2 in rhombomere 4 is regulated by Hoxb I. Genes Dev 1997, I I: | 885-1895.

62. Tumpel S, Cambronero F, Ferretti E, Blasi F, Wiedemann LM, Krumlauf $\mathrm{R}$ : Expression of Hoxa2 in rhombomere 4 is regulated by a conserved cross-regulatory mechanism dependent upon Hoxb I. Dev Biol 2007, 302:646-660.

63. Jungbluth S, Bell E, Lumsden A: Specification of distinct motor neuron identities by the singular activities of individual Hox genes. Development 1999, I 26:275I-2758.

64. Lee J, Platt KA, Censullo P, Ruiz i Altaba A: Gli I is a target of Sonic hedgehog that induces ventral neural tube development. Development 1997, I 24:2537-2552.

65. Ruiz i Altaba A: Combinatorial Gli gene function in floor plate and neuronal inductions by Sonic hedgehog. Development 1998, I 25:2203-22|2.

66. Sasaki H, Hui C, Nakafuku M, Kondoh H: A binding site for Gli proteins is essential for HNF-3beta floor plate enhancer activity in transgenics and can respond to Shh in vitro. Development 1997, 124:1313-1322.

67. Varela-Echavarria A, Pfaff SL, Guthrie S: Differential expression of LIM homeobox genes among motor neuron subpopulations in the developing chick brain stem. Mol Cell Neurosci 1996, 8:242-257.

68. Pattyn A, Vallstedt A, Dias JM, Samad OA, Krumlauf R, Rijli FM, Brunet JF, Ericson J: Coordinated temporal and spatial control of motor neuron and serotonergic neuron generation from a common pool of CNS progenitors. Genes Dev 2003, 17:729-737.

69. Pfaff SL, Mendelsohn M, Stewart CL, Edlund T, Jessell TM: Requirement for LIM homeobox gene IsII in motor neuron generation reveals a motor neuron-dependent step in interneuron differentiation. Cell 1996, 84:309-320.

70. Dubreuil V, Hirsch MR, Jouve C, Brunet JF, Goridis C: The role of Phox2b in synchronizing pan-neuronal and type-specific aspects of neurogenesis. Development 2002, 129:5241-5253.

7I. Pattyn A, Hirsch M, Goridis C, Brunet JF: Control of hindbrain motor neuron differentiation by the homeobox gene Phox2b. Development 2000, 127:1349-1358.

72. Hunt $P$, Wilkinson $D$, Krumlauf R: Patterning the vertebrate head: murine Hox 2 genes mark distinct subpopulations of premigratory and migrating cranial neural crest. Development 1991, I 1 2:43-50. 
73. Grapin-Botton A, Bonnin MA, McNaughton LA, Krumlauf R, Le Douarin NM: Plasticity of transposed rhombomeres: Hox gene induction is correlated with phenotypic modifications. Development 1995, I 2 I:2707-272 I.

74. Itasaki N, Sharpe J, Morrison A, Krumlauf R: Reprogramming Hox expression in the vertebrate hindbrain: influence of paraxial mesoderm and rhombomere transposition. Neuron 1996, 1 6:487-500.

75. Noden DM: The role of the neural crest in patterning of avian cranial skeletal, connective, and muscle tissues. Dev Biol 1983, 96: I44-I65.

76. Noden DM: Patterning of avian craniofacial muscles. Dev Biol 1986, I | 6:347-356.

77. Schneider RA, Helms JA: The cellular and molecular origins of beak morphology. Science 2003, 299:565-568.

78. Arenkiel BR, Trrdik P, Gaufo GO, Capecchi MR: Hoxb I functions in both motoneurons and in tissues of the periphery to establish and maintain the proper neuronal circuitry. Genes Dev 2004, I 8: I539-I552.

79. Sharma K, Sheng HZ, Lettieri K, Li H, Karavanov A, Potter S, Westphal H, Pfaff SL: LIM homeodomain factors Lhx3 and Lhx4 assign subtype identities for motor neurons. Cell 1998, 95:817-828

80. Schilling TF, Prince V, Ingham PW: Plasticity in zebrafish hox expression in the hindbrain and cranial neural crest. Dev Biol 200I, 23I:20I-2I6.

8I. Guidato S, Prin F, Guthrie S: Somatic motoneurone specification in the hindbrain: the influence of somite-derived signals, retinoic acid and Hoxa3. Development 2003, I30:2981-2996.

82. Guthrie S, Lumsden A: Motor neuron pathfinding following rhombomere reversals in the chick embryo hindbrain. Development 1992, I | 4:663-673.

83. Taniguchi H, Shishido E, Takeichi M, Nose A: Functional dissection of drosophila capricious: its novel roles in neuronal pathfinding and selective synapse formation. I Neurobiol 2000, 42: $104-116$.

84. Gould AP, Brookman JJ, Strutt DI, White RA: Targets of homeotic gene control in Drosophila. Nature 1990, 348:308-3I2.

85. Gould AP, White RA: Connectin, a target of homeotic gene control in Drosophila. Development 1992, I I 6: I I63-I I74.

86. Guthrie S, Pini A: Chemorepulsion of developing motor axons by the floor plate. Neuron 1995, I4:III7-II30.

87. Carim-Todd L, Escarceller M, Estivill X, Sumoy L: LRRN6A/LERN I (leucine-rich repeat neuronal protein I), a novel gene with enriched expression in limbic system and neocortex. Eur J Neurosci 2003, 18:3167-3182.

88. Lacy SE, Bonnemann CG, Buzney EA, Kunkel LM: Identification of FLRTI, FLRT2, and FLRT3: a novel family of transmembrane leucine-rich repeat proteins. Genomics 1999, 62:417-426.

89. Lauren J, Airaksinen MS, Saarma M, Timmusk T: A novel gene family encoding leucine-rich repeat transmembrane proteins differentially expressed in the nervous system. Genomics 2003, 8 I:4 | | -42|.

90. Homma S, Shimada T, Hikake T, Yaginuma H: Expression pattern of LRR and Ig domain-containing protein (LRRIG protein) in the early mouse embryo. Gene Expr Patterns 2009, 9:।-26.

91. Hamburger V, Hamilton HL: A series of normal stages in the development of the chick embryo. J Morphol 195I, 88:49.

92. Fukuchi K, Hearn MG, Deeb SS, Smith AC, Dang N, Miyazaki J, Bothwell M, Martin GM: Activity assays of nine heterogeneous promoters in neural and other cultured cells. In Vitro Cell Dev Biol Anim 1994, 30A:300-305.

93. Niwa H, Yamamura K, Miyazaki J: Efficient selection for highexpression transfectants with a novel eukaryotic vector. Gene 1991, 108:193-199.

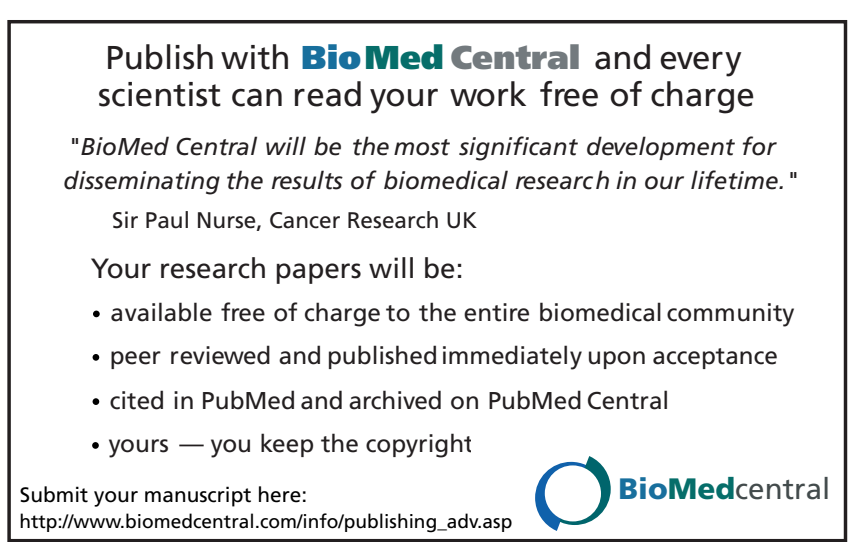

